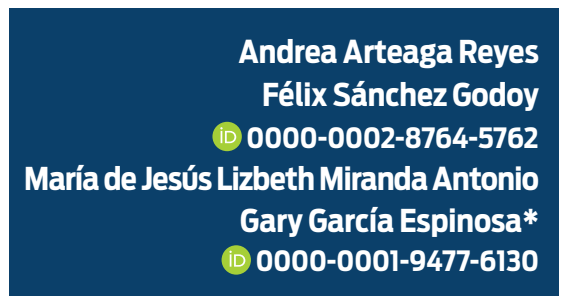

Departamento de Medicina y Zootecnia de Aves, Facultad de Medicina Veterinaria y Zootecnia, UNAM.

* Autor para correspondencia: Correo electrónico: gary@unam.mx
Recibido: 2020-09-13 Aceptado: 2021-08-18 Publicado: 2021-10-05

Información y declaraciones adicionales en la página 10

@Derechos de autor: Andrea Arteaga Reyes et al. 2021

acceso abierto

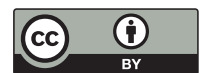

\section{Hiperostosis multicéntrica (osteopetrosis) en un agapornis (Agapornis roseicollis)}

\section{Resumen}

Descripción del caso. Agapornis macho de un año de edad que presentó diarrea, hiporexia, claudicación del miembro pélvico derecho y postración.

Hallazgos clínicos. Trastorno respiratorio bacteriano y trastorno del aparato musculoesquelético en el miembro pélvico derecho asociado a neoformación.

Tratamiento y evolución. Administración de antibiótico, analgésico, y antiinflamatorio no esteroide. El trastorno respiratorio se resolvió clínicamente, pero no la claudicación que aumentó de intensidad por lo cual el propietario solicitó la eutanasia.

Pruebas de radiología y laboratorio. Se realizaron estudios radiográficos en proyección ventrodorsal y laterolateral para el diagnóstico de la claudicación, así como un estudio citológico del tejido de neoformación del miembro pélvico derecho. La necropsia e histopatología fueron complementarias después de la eutanasia.

Relevancia clínica. La hiperostosis en aves de ornato y compañía es rara, se recomienda considerar el diagnóstico diferencial con trastornos óseos que incluyan engrosamiento y deformidad de huesos como deficiencias nutricionales, traumatismo, tumores primarios de hueso y enfermedad genética.

Palabras clave: hiperostosis, osteopetrosis, psitácido, Agapornis roseicollis.

\section{Una forma de citar este artículo:}

Arteaga Reyes A, Sánchez Godoy F, Miranda Antonio M de JL, García Espinosa G. Hiperostosis multicéntrica (osteopetrosis) en un agapornis (Agapornis roseicollis). Clínica veterinaria: abordaje diagnóstico y terapéutico. 2021;7: e62202173. doi: 


\section{Multicenter hyperostosis (osteopetrosis) in a lovebird (Agapornis roseicollis)}

\section{Abstract}

Description of the case. One-year-old male lovebirds that presented with diarrhea, hyporexia, claudication of the Musculo skeletal apparatus in the right pelvic limb and prostation.

Clinical findings. Bacterial respiratory disorder and disorder of the musculoskeletal apparatus in the right pelvic limb associated with neoformation.

Treatment and evolution. It was administrated antibiotic, analgesic, and nonsteroidal anti-inflammatory drugs. The respiratory disorder was resolved clinically, but not the claudication that increased in intensity, so the owner requested euthanasia.

Radiology and laboratory tests. Radiographic studies were performed in ventrodorsal and latero-lateral projection for the diagnosis of claudication, as well as a cytological study of the neoformation tissue of the right pelvic limb. Necropsy and histopathology were complementary after euthanasia.

Clinical relevance. Hyperostosis in ornamental and companion birds is rare, it is recommended to consider the differential diagnosis with bone disorders that include thickening and deformity of bones as nutritional deficiencies, trauma, primary bone tumors and genetic diseases.

Keywords: hyperostosis, osteopetrosis, psittacid birds, Lovebirds, roseicollis 


\section{Descripción del caso clínico}

A finales de noviembre de 2019 se remitió al Hospital de Aves de Ornato y Compañía, de la FMVZ-UNAM un ejemplar de Agapornis roseicollis de aproximadamente un año de edad. El ave fue adquirida al mes de edad de un criadero. Se le alimentaba con alpiste, otras semillas no identificadas, "chochitos" de colores, manzana, croquetas para aves (composición desconocida) y agua del grifo. Recibía diariamente los rayos del sol directo y por las tardes se alojaba en el interior del hogar. Dos semanas antes de la consulta, el ave tuvo diarrea, hiporexia, claudicaba del miembro pélvico derecho y se encontraba postrada la mayor parte del tiempo. Antes de los primeros signos clínicos, el ave se caía de una altura de unos $110 \mathrm{~cm}$.

\section{Hallazgos clínicos e interpretación}

El ave se encontraba alerta y responsiva a los estímulos ambientales, le faltaban algunas plumas coberteras, tenía diarrea y estaba deshidratada. En el examen físico general se observó abundante secreción con apariencia mucosa en la cavidad oral, y la ranfoteca rota en capas y frágil. En la auscultación se detectaron estertores secos leves. Mediante la palpación de los músculos pectorales, se percibió diferencia en el tamaño entre el músculo pectoral izquierdo y el derecho. El miembro pélvico derecho (MPD) estaba aumentado de tamaño a nivel de la articulación femorotibiotarso, donde el ave era muy sensible a la palpación. El peso corporal fue de 37 gramos, de acuerdo a una investigación de Carpenter en el 2018, representa el 23.8\% por debajo del rango de 42 a 49 gramos de la especie y su condición corporal en los músculos pectorales era dos de cinco, es decir, baja.

El Agapornis roseicollis se ingresó y mantuvo en el área de terapia intensiva con un diagnóstico presuntivo de trastorno respiratorio asociado a su exposición a los cambios bruscos de temperatura y un trastorno del aparato músculo-esquelético en el miembro pélvico derecho asociado a traumatismo por caída.

\section{Tratamiento y evolución}

El ave recibió hidratación con $1.8 \mathrm{~mL}$ de solución de Hartman a $38{ }^{\circ} \mathrm{C}$ vía subcutánea cada doce horas por tres días. El tratamiento respiratorio consistió en amoxicilina con ácido clavulánico ( $125 \mathrm{mg} / \mathrm{kg}$ de peso vivo vía oral) cada doce horas por diez días. El tratamiento para el trastorno musculoesquelético fue tramadol (30 mg/kg de peso vivo vía oral) cada doce horas por cuatro días y meloxicam (0.2 mg/kg de peso vivo vía oral) cada doce horas por diez días. También se administró de forma profiláctica silimarina (Cardo mariano, $50 \mathrm{mg} / \mathrm{kg}$ de peso vivo vía oral) cada doce horas por diez días, omega 3 (616 mg/ $\mathrm{kg}$ de peso vivo vía oral) cada 24 horas por diez días, y vitamina E ( $400 \mathrm{mg} / \mathrm{kg}$ de peso vivo vía oral) cada 24 horas por diez días. El trastorno respiratorio desapareció clínicamente al término del tratamiento, pero no la claudicación con diagnóstico radiográfico presuntivo de neoplasia y diagnóstico citológico presuntivo de osteosarcoma. 


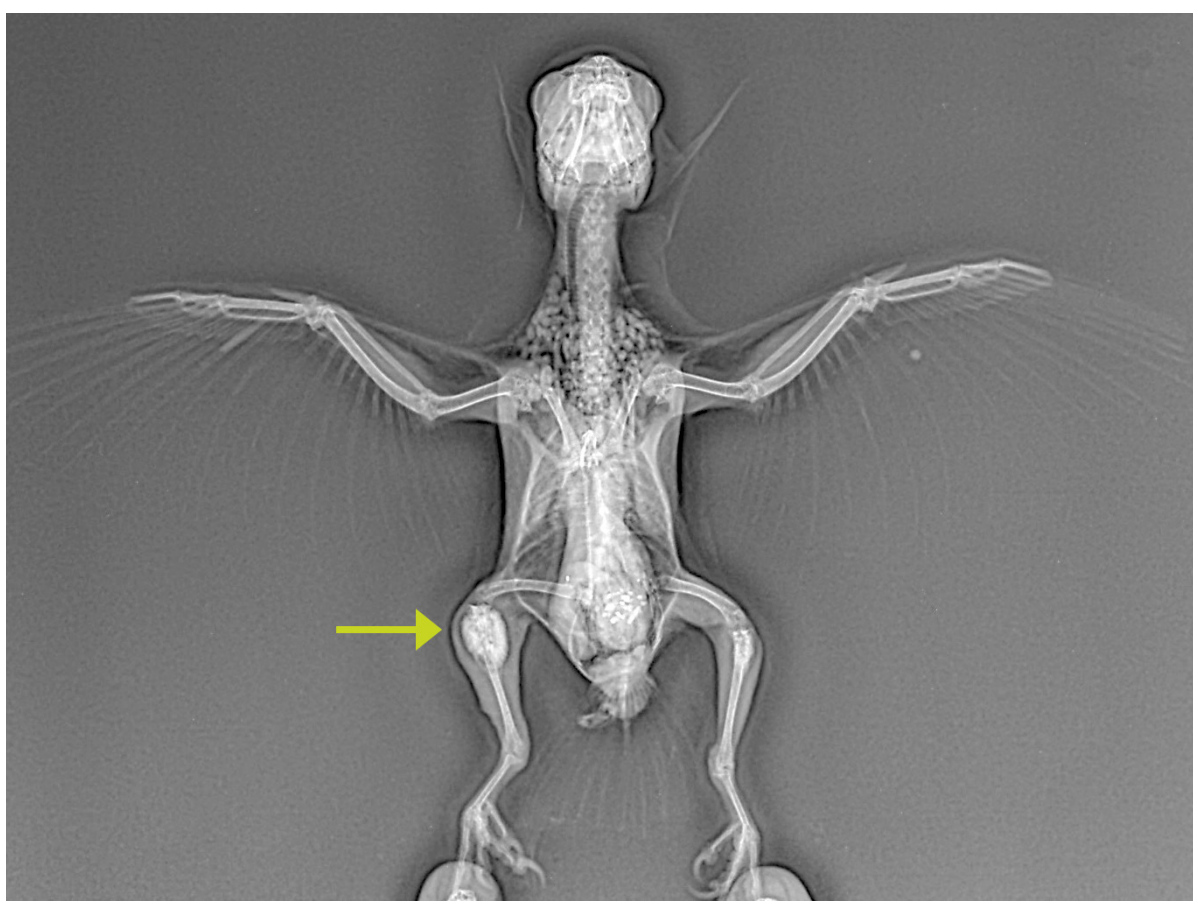

Figura 1. Proyección ventrodorsal del 25/11/2019. Se observa un aumento de radio-opacidad en la epífisis proximal del tibiotarso en ambos miembros pélvicos, es mayor el cambio de radio-opacidad en el miembro pélvico derecho (flecha).

\section{Pruebas de radiología y laboratorio Estudio radiográfico}

El día que ingreso el ave (25/11/2019) se realizó un estudio radiográfico en posición ventrodorsal y laterolateral para descartar una fractura. El análisis radiográfico mostró un aumento de radio-opacidad en la epífisis proximal del tibiotarso en ambos miembros pélvicos, pero con mayor severidad en el derecho (Figura 1), quince días después se realizó otro análisis radiográfico en el que la lesión se extendió hacia la diáfisis de ambos tibiotarsos (Figura 2 y 2.1), la cual siguió aumentando a los 28 días posteriores al primer estudio (Figura 3 y 3.1).

\section{Citología}

Después del primer estudio radiográfico se decidió obtener una muestra por punción con aguja fina del tejido de nueva formación localizado en el tibiotarso derecho, y realizar citología con tinción de Diff-Quik. El análisis mostró escasos grupos de células mesenquimatosas, redondas a ovaladas, con mínima anisocariosis, citoplasma moderado y finamente vacuolado, y el diagnóstico probable fue osteosarcoma (Figura 4A).

Debido a la mala condición del paciente, por la baja de peso, depresión y a un incremento en la claudicación, el propietario solicitó la eutanasia del ave. Se realizó la eutanasia con sobredosis de isoflurano según la NORMA Oficial Mexicana NOM-062-/ZOO-1999: especificaciones técnicas para la producción y uso de los animales de laboratorio. El cadáver fue enviado para realizar necropsia e histopatología al laboratorio de diagnóstico e investigación en enfermedades de las aves del Departamento de Medicina y Zootecnia de Aves, de la FMVZ-UNAM. 


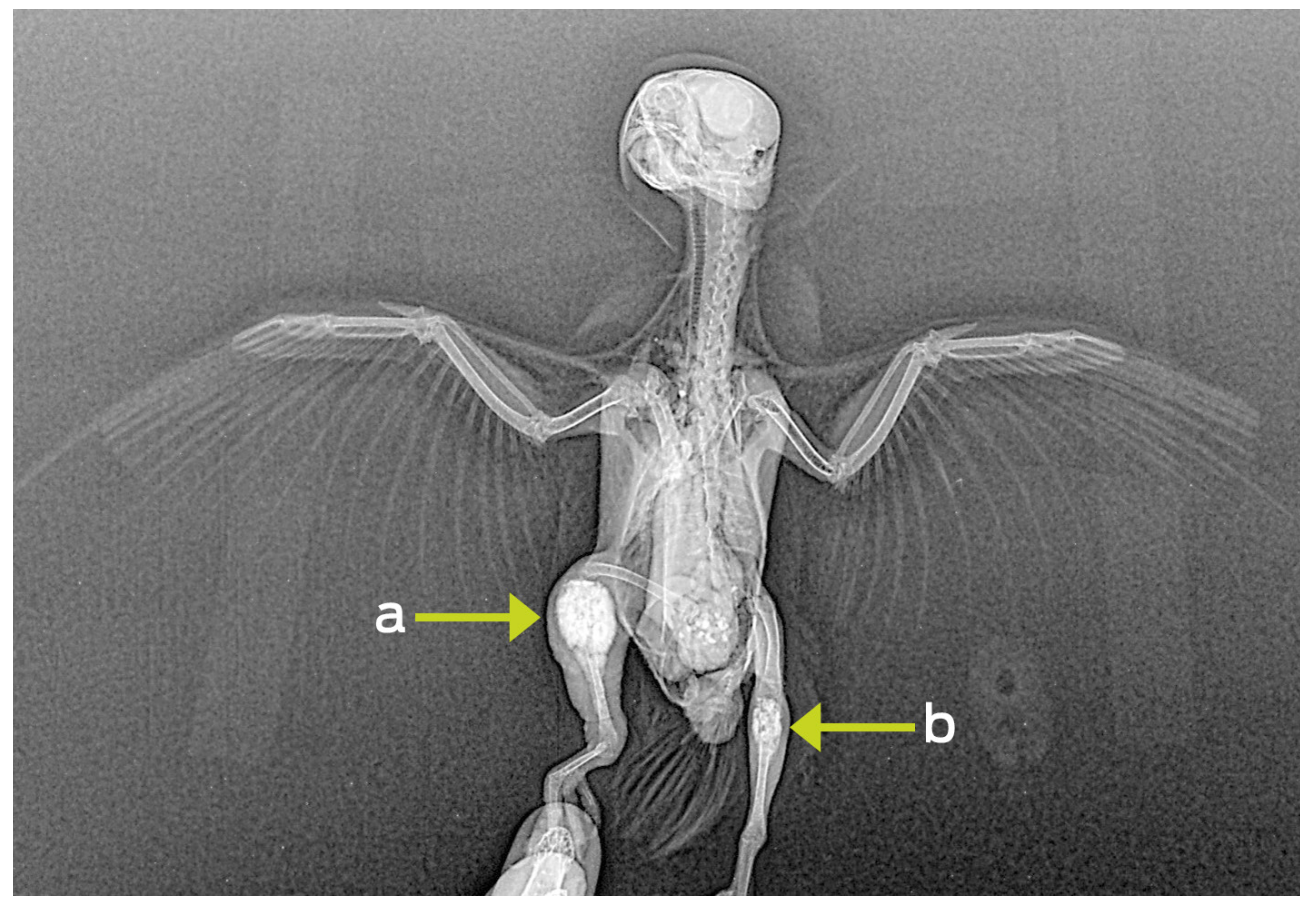

Figura 2. Proyección ventrodorsal tomada quince días después del primer estudio radiográfico. Se observó un aumento de radio-opacidad en la epífisis proximal del tibiotarso, que se extendió un poco hacia la diáfisis en ambos miembros

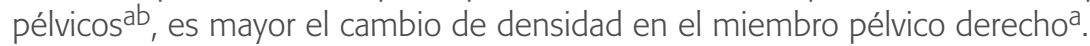

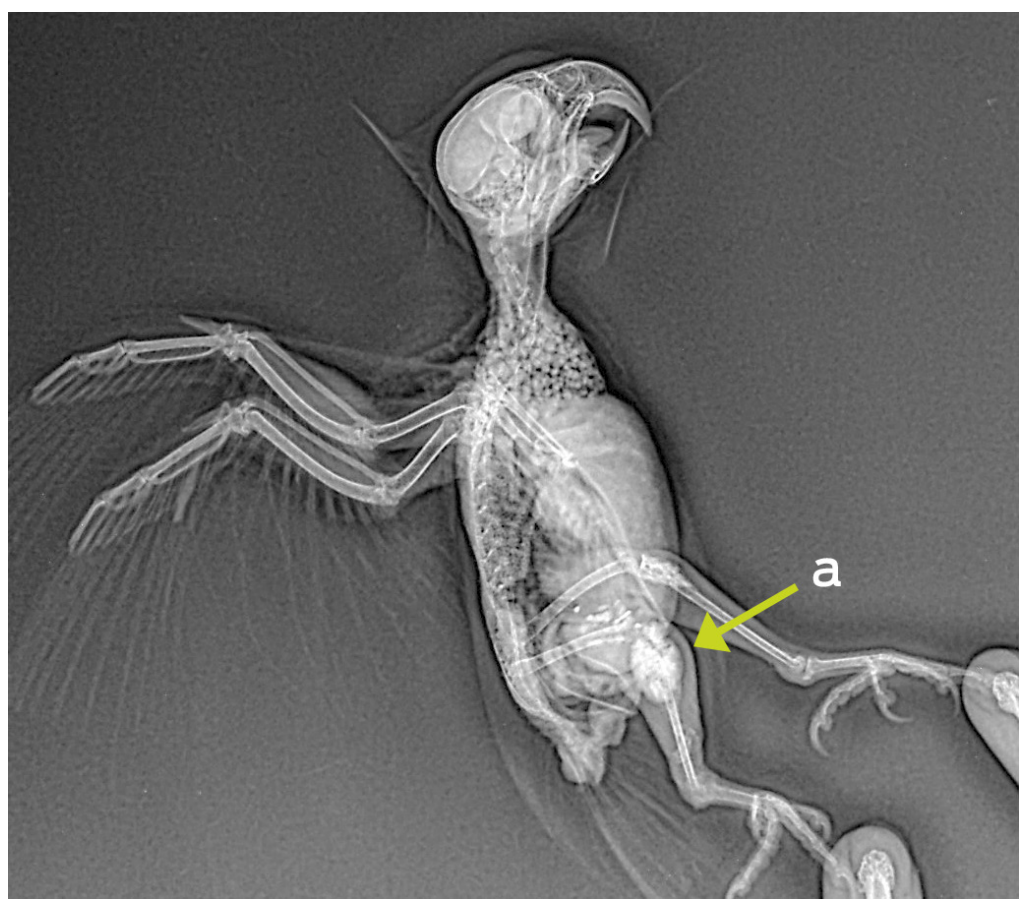

Figura 2.1. Proyección laterolateral. Se observa un aumento de radio-opacidad en la epífisis proximal del tibiotarso en ambos miembros pélvicos, es mayor el cambio de radio-opacidad en el derechoa. 


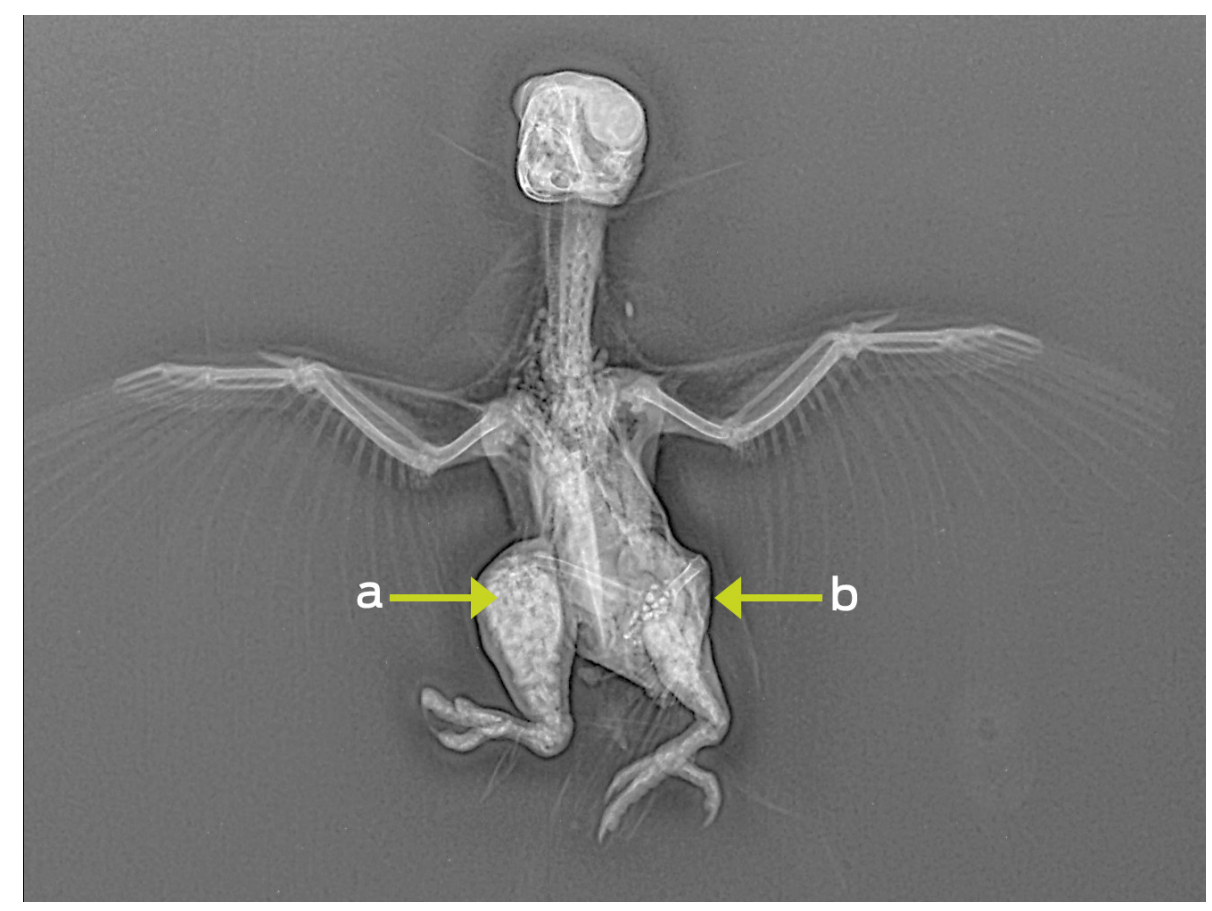

Figura 3. Proyección ventrodorsal, 28 días después del segundo estudio radiográfico. Se observó un aumento de radioopacidad en todo el miembro pélvico derecho ${ }^{\mathrm{a}}$, y toda la región del tibiotarso del miembro pélvico izquierdob.

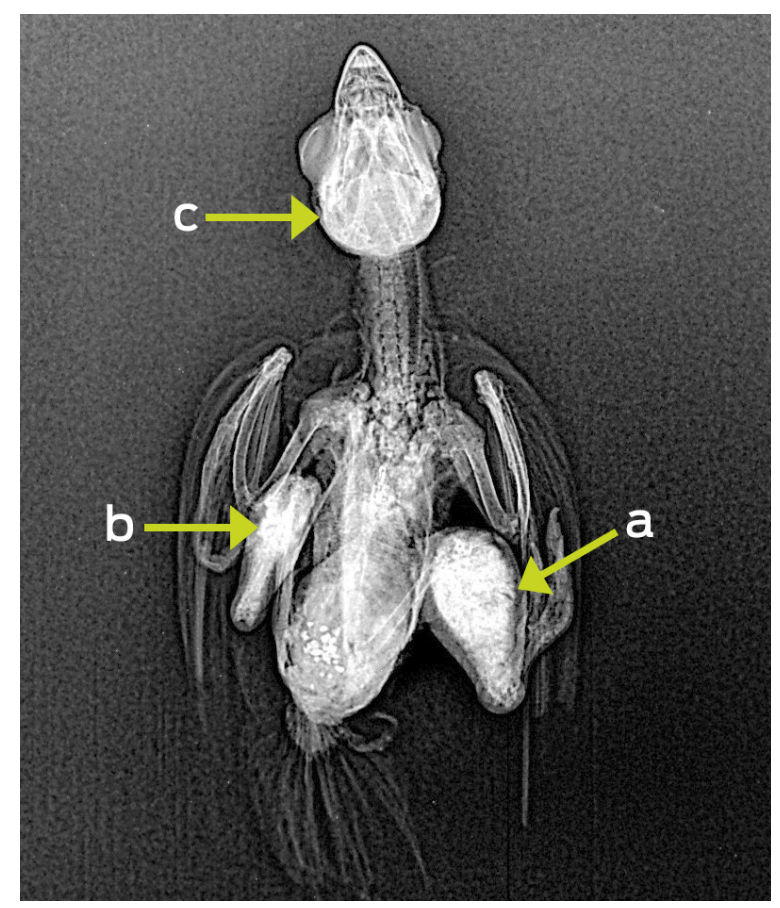

Figura 3.1. Proyección dorsoventral 28 días después del segundo estudio radiográfico. Se observó un aumento de radioopacidad en todo el miembro pélvico derecho ${ }^{a}$, y toda la región del tibiotarso del miembro pélvico izquierdo ${ }^{b}$ y un aumento de radio-opacidad en el cráneo del lado izquierdoc . 


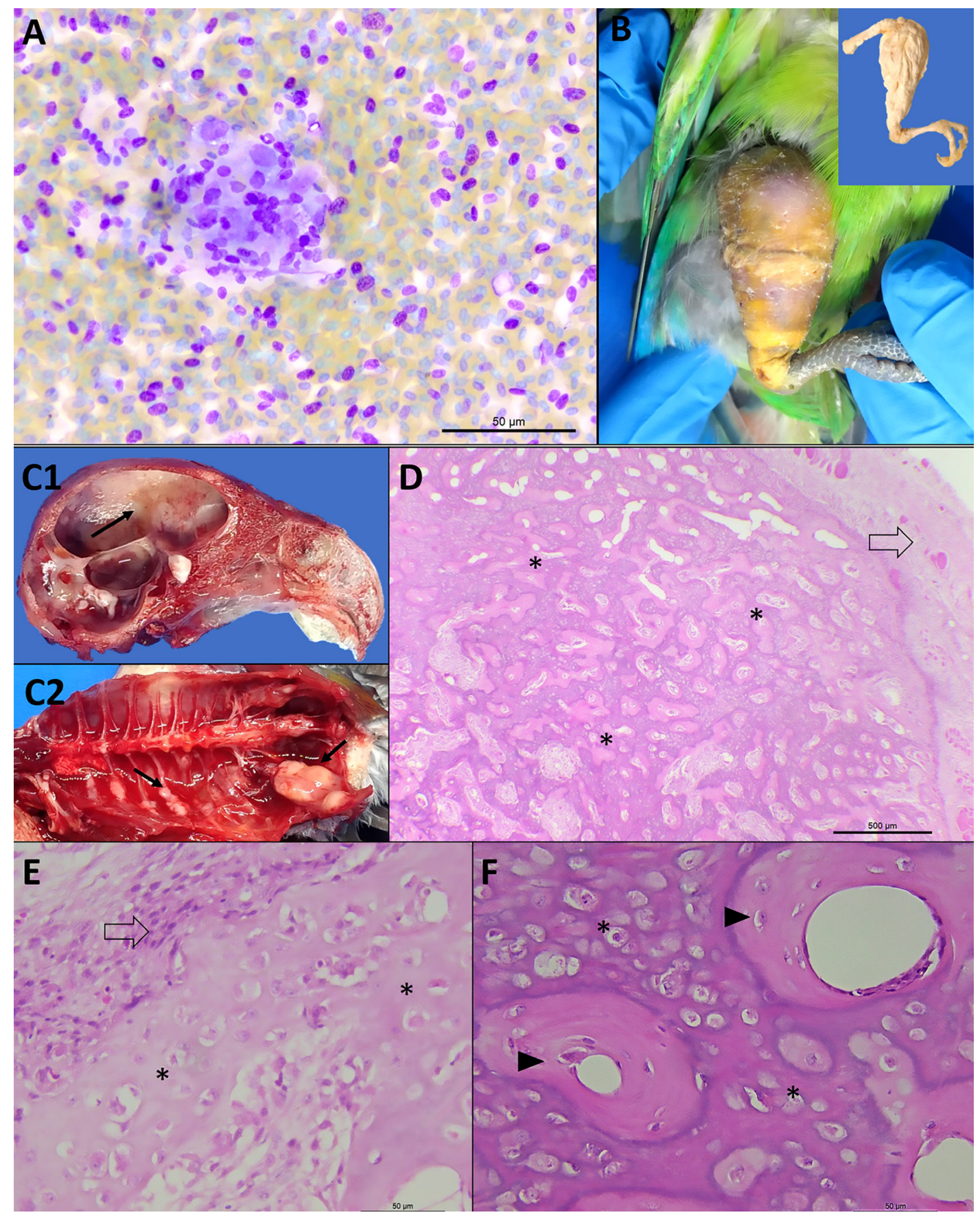

Figura 4. A) Citología del tibiotarso. Sobre un fondo de eritrocitos se observó un grupo de células mesenquimatosas, de núcleo redondo a ovalado, con moderada anisocariosis y abundante cantidad de citoplasma, en ocasiones finamente vacuolado. Tinción Diff-Quik, barra $50 \mu \mathrm{m}$. B) El miembro pélvico derecho se apreció gravemente engrosado, con la piel de color amarillo, al disecar los músculos se encontró un tejido de nueva formación (inserto) blanco, duro, que crepitaba al corte e involucraba al tibiotarso, también se extendía al fémur y al tarsometatarso. C) Los huesos del cráneo del lado izquierdo (C1), algunas costillas y la pelvis del lado derecho (C2), exhibían tejidos de neoformación similares a los descritos en el tibiotarso (flechas). D) Fotomicrografía del tibiotarso, se apreció atrofia de los músculos esqueléticos (silueta de flecha) y proliferación grave difusa circunferencial del hueso cortical y trabecular (hiperostosis: asteriscos) con obliteración de la cavidad medular. Tinción H\&E, barra $500 \mu \mathrm{m}$. E) Fotomicrografía del tibiotarso, en el periostio se observó proliferación de células mesenquimales de núcleo y citoplasma alargado (silueta de flecha), y el hueso cortical (asteriscos) exhibió proliferación moderada de osteocitos. Tinción H\&E, barra $50 \mu \mathrm{m}$. F) Fotomicrografía de tibiotarso, las zonas de hiperostosis se caracterizaron por la formación de trabéculas óseas y osteonas (cabeza de flecha), separadas por tejido óseo (asteriscos) con osteocitos en diferentes grados de maduración. Tinción H\&E, barra 50 m. 


\section{Necropsia}

El ave presentaba una condición corporal baja, el ojo del lado izquierdo mostraba moderada exoftalmia. El miembro pélvico del lado derecho se apreció gravemente engrosado en la región proximal de la pierna de aproximadamente cuatro veces su tamaño normal con la piel de color amarillo (Figura 4B). Al disecar los músculos se observó un tejido de nueva formación de color blanco, duro al tacto, que crepitaba al corte e involucraba la epífisis y la diáfisis del tibiotarso (Figura 4B). El miembro pélvico del lado izquierdo tenía una lesión similar, pero en grado moderado. Los huesos frontales, parietales y esfenoides del lado izquierdo del cráneo se apreciaron engrosados y de color blanco (Figura 4Cl). En la cara dorsal del esternón se observaron múltiples nódulos de color blanco, duros al tacto, cuyas dimensiones mayores y menores oscilaban entre 0.6 y $0.2 \mathrm{~cm}$, mal delimitados y que se extendían a la cara ventral y a los músculos pectorales profundos. Entre la segunda y la séptima costilla del lado derecho, y el isquion y el pubis del mismo lado, se exhibían tejidos de neoformación similares a los descritos en el esternón y el tibiotarso (Figura 4C2). El resto de los aparatos y sistemas no presentaron cambios patológicos significativos.

En la necropsia se colectaron muestras de todos los órganos donde se observaron las lesiones. Los órganos se fijaron en formol amortiguado por $24 \mathrm{~h}$ y se procesaron por la técnica de rutina de inclusión en parafina y se tiñeron con H\&E. Los huesos se descalcificaron con solución de ácido fórmico y clorhídrico, por tres días, posteriormente fueron procesados de la misma forma que los otros tejidos.

\section{Histopatología}

Diáfisis del tibiotarso. La corteza consistía de un engrosamiento grave difuso y circunferencial con obliteración de la cavidad medular por un aumento del tejido óseo (interpretado como hiperostosis) (Figura 4D). La hiperostosis se caracterizó por abundante cantidad de hueso cortical y trabecular de grosor variable y con gran cantidad de osteocitos moderadamente diferenciados que se encontraron en lagunas de tamaño variable.

Los conductos de Havers eran numerosos, estaban distendidos y se formaron algunas osteonas, y en el periostio proliferaron varias capas de células mesenquimales de núcleo alargado, hipercromático con mínima anisocariosis y con citoplasma fusiforme y ligeramente eosinofilico (Figura 4E y F). En contacto estrecho con las trabéculas óseas se apreció proliferación discreta de osteoblastos y células mesenquimatosas; asimismo, se hallaron osteoclastos en las lagunas de Howship.

Cambios similares a los descritos se observaron en los huesos de costilla, esternón, pelvis y cráneo. El diagnóstico morfológico fue hiperostosis subperióstica y endosteal grave difusa circunferencial con obliteración de la cavidad medular. Se revisaron secciones de otros órganos sin que se apreciaran cambios patológicos significativos.

\section{Discusión y relevancia clínica}

La hiperostosis subperióstica y endosteal, circunferencial, en huesos largos de miembros pélvicos, esternón, costillas y cráneo en esta ave, es compatible con un 
proceso de hiperostosis también conocido como osteopetrosis. La osteopetrosis es una enfermedad esporádica en las aves domésticas (Gallus gallus). Las aves afectadas usualmente están retrasadas en el crecimiento, pálidas, caminan con dificultad y claudican, como ocurrió en este caso.

Macroscópicamente se observan cambios en la diáfisis del tibiotarso o tarsometatarso, las lesiones son usualmente bilaterales y simétricas, y microscópicamente se aprecia hiperostosis del periostio y el endostio, similar a este caso $(1,2)$. Este trastorno se asocia con la infección por un alfaretrovirus que ocasionan el complejo leucosis/sarcoma, caracterizado por el desarrollo de varias neoplasias como linfomas, mieloblastomas, mielocitomas, hemangiomas, osteosarcomas, fibrosarcomas, etcétera; algunas de las cepas virales también pueden desarrollar el proceso de osteopetrosis como la MAV-2 que pertenece al subgrupo B $(2,3,4)$.

La causa de la hiperostosis en el agapornis se desconoce, pero puede ser consecuencia de un proceso viral o un defecto genético en la maduración de los osteoblastos, por lo que se podría realizar microscopia electrónica, inmunohistoquímica y biología molecular para determinar la causa; sin embargo, en este caso dichas pruebas no fueron realizadas. En otras especies, la osteopetrosis se ha presentado en perro de la raza pastor australiano con padres consanguíneos (5) y en humanos se considera de origen genético ${ }^{(6)}$.

La revisión de literatura evidencia que éste sería el primer caso de osteopetrosis en aves de ornato y compañía. Las enfermedades por alfaretrovirus y defectos genéticos en aves de producción de carne y huevo han sido eliminadas debido a programas de detección temprana del virus o los genes no deseables por pruebas moleculares de las aves progenitoras portadoras con su consiguiente eliminación de los programas de reproducción (7), por lo que es necesario estandarizar pruebas moleculares de consanguinidad y de alfaretrovirus en las aves del criadero de donde se adquirió el Agapornis roseicollis para seleccionar aves libres con estas características como parte de un programa de control y erradicación. Asimismo, estas pruebas pueden realizarse a pacientes sospechosos de la enfermedad para el diagnóstico.

Los diagnósticos diferenciales para casos de deformidad en huesos largos, claudicación y aumento en la radio-opacidad del hueso en aves de ornato y compañía, incluyen deficiencias nutricionales y procesos neoplásicos primarios de hueso. El raquitismo se caracteriza por retención de cartílago en la placa de crecimiento y deformidad del hueso y no cursan con hiperostosis $(2,8)$. Los tumores primarios de hueso como los osteomas/osteosarcomas y condromas/condrosarcomas, exhiben células neoplásicas con criterios de malignidad; generalmente estas neoplasias están en un solo hueso y principalmente generan metástasis en vísceras como el hígado y el pulmón (9). Este caso difiere en la formación de neoplasias, porque en las lesiones macro- y microscópicas se encontraron células óseas sin características de malignidad e hiperostosis con cambios simultáneos en múltiples huesos. Lesiones sincrónicas sin evidencia de metástasis en vísceras. No hay tratamiento médico o quirúrgico para esta enfermedad.

Este es el primer caso documentado en este hospital de aves, cuyas lesiones son similares a osteopetrosis en aves de ornato y compañía. Considérese como diagnóstico diferencial en casos de engrosamiento y deformidad de huesos que se asocien a deficiencias nutricionales, tumores primarios de hueso o enfermedad genética, que por el momento no tienen tratamiento específico. 


\section{Financiamiento}

Proyecto PAPIME PE205719.

\section{Agradecimientos}

Al técnico académico Alfredo Díaz Estrada por el apoyo en el procesamiento de muestras histológicas.

\section{Conflictos de interés}

Los autores declaran que no hay conflicto de interés para la publicación de ese caso.

\section{Contribución de los autores}

Andrea Arteaga Reyes, María de Jesús Lizbeth Miranda Antonio y Gary García Espinosa participaron en el diagnóstico y tratamiento y escribieron el artículo.

Félix Sánchez Godoy realizó la necropsia, citología, y la histopatología y escribió el artículo.

\section{Referencias}

1. Simpson CF, Sanger VL. A review of avian osteopetrosis: comparisons with other bone diseases. Clin Orthop Relat Res. 1968;58:271-281.

2. Fadly AM, Nair V. Neoplastic diseases: leukosis/sarcoma group. En: YM Saif, AM Fadly, JR Glisson, LR McDougald, LK Nolan, DE Swayne (editores). Diseases of poultry. 12a ed. lowa (US): Blackwell Publishing; 2008.

3. Dafour-Zavala L, Swayne DE, Glisson JR, Pearson JE, Reed WM, Jackwood MW, Woolcock PR. Laboratory manual for the isolation: identification and characterization of avian pathogens. 5a ed. Jacksonville, Florida (US): American Association of Avian Pathologists; 2008.

4. Fletcher OJ \& Abdul-Aziz T. Avian histopathology. 3a ed. Madison Wisconsin (US): American Association of Avian Pathologists; 2008.

5. Less GE \& Sautter JH. Anemia and osteopetrosis in a dog. J. Am. Vet. Med. Assoc. 1979;175(8):820-824.

6. Wu CC, Econs MJ, DiMeglio LA, Insogna KL, Levine MA, Orchard PJ, Miller WP, Petryk A. Rush ET, Shoback DM, Ward LM, Polgreen LE. Diagnosis and management of osteopetrosis: consensus guidelines from the osteopetrosis working group. J. Clin. Endocrinol. Metab. 2017;102(9):3111-3123. doi: 10.1210/ jc.2017-01127.

7. Payne LN \& Nair V. The long view: 40 years of avian leukosis research, Avian Pathology. 2012;41(1):11-19. doi:10.1080/03079457.2011.646237.

8. Schmidt RE, Reavill DR, Phalen DN. Pathology of pet and aviary birds. 2a ed. lowa (US): Wiley Blackwell; 2015.

9. Dittmer $K E$, French AF, Thompson DJ, Buckle KN, Thompson KG. Primary bone tumors in birds: a review and description of two new cases. Avian Dis. 2012;56(2):422-426. doi: 10.1637/9854-071911-Case.1 